\author{
FACULDADE EDUCACIONAL DA LAPA - FAEL \\ CURSO DE LICENCIATURA EM LETRAS - LÍNGUA PORTUGUESA/ESPANHOL
}

\title{
O HOMESCHOOLING EM LÍNGUA PORTUGUESA: CONTRIBUIÇÕES À APRENDIZAGEM DO ESTUDANTE DO ENSINO REGULAR ${ }^{1}$
}

\author{
Camila Dias Manoel ${ }^{2}$ \\ Orientadora: Prof. ${ }^{\text {a }}$ Dr. ${ }^{\text {a }}$ Mara Eli de Matos $^{3}$
}

\begin{abstract}
RESUMO
O homeschooling vem ganhando destaque no Brasil com o Projeto de Lei $2401 / 2019$, que visa regulamentar essa modalidade de ensino. Mas quais seriam os benefícios dessa modalidade ao estudante do ensino regular, especialmente ao estudante regular de Língua Portuguesa? Encontrou-se que alguns métodos de homeschooling, como "estudo por temas", e valores preconizados por essa modalidade, como autonomia, autodidatismo, empreendedorismo, personalização do estudo, participação dos pais, podem beneficiar estudantes do ensino regular, e já são uma realidade em escolas que buscam melhorar a qualidade de ensino, como a Escola da Ponte. A metodologia utilizada é a pesquisa bibliográfica de fontes como Pisa 2015, Pessoa, Novaes e Aned.
\end{abstract}

PALAVRAS-CHAVE: homeschooling; ensino regular; língua portuguesa; leitura; Pisa.

\section{RESUMEN}

La homeschooling ha ganado destaque en Brasil con el Proyecto de Ley 2401/2019, que busca regular dicha modalidad de ensenãnza. Sin embargo, cuáles serían los beneficios de esa modalidad al estudiante de enseñanza regular, especialmente al estudiante regular de Lengua Portuguesa? Se encontró que unos métodos usados en homeschooling, como "estudio por temas", y valores defendidos por dicha modalidad, como autonomía, autoaprendizaje, personalización del estudio, participación de los padres, pueden traer beneficios al estudiante de la educación regular, y ya son una realidad en escuelas que buscan mejorar la calidad de enseñanza, como la Escola da Ponte. El método usado es la investigación bibliográfica de fuentes como Pisa 2015, Pessoa, Novaes y Aned.

PALABRAS-CLAVE: homeschooling; enseñanza regular; lengua portuguesa; lectura.

\footnotetext{
${ }_{1}^{1}$ Artigo apresentado ao curso de licenciatura em Letras - Língua Portuguesa/Espanhol. Faculdade Educacional da Lapa (Fael). 16 de novembro de 2019.

${ }_{2}^{2}$ Acadêmico do curso de licenciatura em Letras - Língua Portuguesa/Espanhol. São Bento do Sul/SC, 2019. camila.diasmanoel@gmail.com.

3 Professora doutora em Engenharia de Bioprocessos e Biotecnologia, professora da Fael Curitiba/PR. 2019.
} 


\section{INTRODUÇÃO}

Nosso interesse pelo ensino domiciliar, ou homeschooling, começou concomitantemente com o interesse pela modalidade de ensino a distância. As duas modalidades, a nosso ver, possibilitam ao estudante a flexibilidade de estudar de qualquer lugar, pelo computador, pelo smartphone ou por tablet, em qualquer momento e escolhendo o assunto de que quer tratar, bastando que o estudante, sozinho ou com o auxílio do tutor, organize seu plano de estudos e o tempo de estudo para que possa acompanhar e avançar progressivamente nas matérias de interesse ou obrigatórias.

Esse interesse, no entanto, já não está restrito a alguns setores ou algumas famílias, mas vem ganhando espaço e discussão há algum tempo, e mais recentemente com um novo projeto de lei (2019) que visa adequar a modalidade de ensino domiciliar com avaliações sistemáticas e uma séries de regras que possibilitam ao estudante e à família comprovarem o avanço dos estudos. Se antes o acesso à informação era difícil por falta de escolas, mobilidade, bibliotecas que ficavam longe da residência do estudante, hoje essa deficiência vem diminuindo em razão das novas tecnologias, do acesso à internet (e consequentemente a conteúdos que podem abarcar ou ultrapassar o volume encontrado em bibliotecas físicas) e da maior quantidade de instituições de ensino público e privado.

Tendo isso em vista, nesta pesquisa procurou-se discutir o ensino domiciliar (homeschooling) em Língua Portuguesa e as possíveis contribuições aos estudantes do ensino regular, tendo como método a pesquisa bibliográfica descritiva de abordagem qualitativa.

O objetivo geral foi entender se o ensino domiciliar funciona como reforço ou alternativa à escola regular no Brasil.

Com isso, apresentamos o que é o ensino domiciliar e estatísticas de desempenho de nossos alunos brasileiros (Pisa 2015); discutimos as possíveis contribuições do homeschooling ao ensino regular de Língua Portuguesa com base na literatura da área, os principais métodos utilizados no homeschooling e um exemplo de uma escola que mescla esses métodos dentro do espaço tradicional da escola. 
É importante destacar aqui a atualidade e relevância do tema, que ganhou maior espaço na mídia e no plenário desde 2018. O Projeto de Lei oㅡ 2401/2019, que "Dispõe sobre o exercício do direito à educação domiciliar", já foi assinado pelo presidente e está "Aguardando Constituição de Comissão Temporária pela Mesa" (BRASIL, 2019, não paginado).

$\mathrm{Na}$ Exposição de Motivos Interministerial № 00019/2019, que acompanha o projeto de lei, e encaminhada ao presidente, atenta-se para o conceito de "educação domiciliar" (ED), do qual compartilhamos: "[...] educação domiciliar consiste no regime de ensino de crianças e de adolescentes [...] dirigido pelos pais ou por responsáveis." (BRASIL, 2019, p. 7).

Conceito que vai ao encontro do que a Associação Nacional de Educação Domiciliar (Aned) também entende como "educação domiciliar" (CONCEITO, 2019, não paginado). Para a Aned, a ED caracteriza-se principalmente por ser uma (i) "educação integral", já que "os pais se responsabilizam por todos os aspectos da educação dos filhos"; (ii) uma "Educação em todo o tempo", uma vez que "Tudo pode ser uma oportunidade para aprender", e pode ocorrer em qualquer lugar, "no lar, na rua, na vizinhança, em passeios"; (iii) um "Treino para o aprendizado", uma vez que os pais, nessa modalidade, são mediadores entre os filhos e o conhecimento; aqui os pais "não precisam entender de todos os assuntos. Precisam apenas [...] levá-los a questionar, pesquisar, buscar o conhecimento. Ensiná-los a pensar de forma lógica, conduzi-los ao autodidatismo, à autonomia", porque, ao contrário de uma educação conteudista, o aluno de ED trabalha o(a):

- Desenvolvimento do intelecto;

- Formação de habilidades;

- Equilíbrio emocional;

- Sociabilidade;

- Espiritualidade. (CONCEITO, 2019, não paginado).

Em todo caso, destaque-se, conforme Andrade, esse processo "deve ser compreendido não em termos de lugares nos quais ocorre (escola, casa, distância), mas sim em termos de agentes (professor, pais, sociedade, criança, adolescente, jovem, etc.)" (ANDRADE, 2014, p. 20).

Essa modalidade de educação, com as características apresentadas, conhecida também por seu termo em inglês homeschooling, é difundida em todo o globo, 
"permitida ou regulamentada em mais de 60 países, nos cinco continentes" (HISTÓRICO, 2019, não paginado).

\section{ENSINO REGULAR E HOMESCHOOLING}

O Pisa, por sua sigla em inglês, é o Programa Internacional de Avaliação de Estudantes coordenado pela Organização para Cooperação e Desenvolvimento Econômico (OCDE), no Brasil organizado pelo Instituto Nacional de Estudos e Pesquisas Educacionais Anísio Teixeira (Inep). Trata-se de um sistema de avaliação comparada da qualidade da educação realizado a cada três anos com alunos do ensino regular matriculados a partir do $7^{\circ}$ ano do ensino fundamental. Uma das áreas de conhecimento avaliadas pelo Pisa é a leitura, mas também traz outros indicadores, como variáveis demográficas, socioeconômicas e educacionais correlacionadas ao desempenho dos alunos. (PROGRAMA..., 2015).

Não obstante, a última prova divulgada, de 2015, trouxe resultados abaixo da média esperada para o Brasil [os dados apresentados aqui são do próprio relatório do Pisa (OECD, 2015)]: dos 70 países participantes, o Brasil ficou na 59ª posição em leitura: o desempenho dos alunos brasileiros foi de 407 pontos ${ }^{4}$, abaixo da média, de 493 pontos. Já o primeiro lugar em leitura foi para Cingapura, que alcançou 535 pontos. Portugal fez 498 pontos, o Chile, 459.

Como dados contextuais, o relatório do Pisa informa ainda que o PIB per capita do Brasil (USD 15. 893) está bem abaixo da média dos países-membros da OCDE (USD 39 333), assim como o gasto por aluno entre 6 e 15 anos de idade: no Brasil é de USD 38 190, 42 \% da média dos países da OCDE, USD 90. 294, mas em 2002 essa proporção era de $32 \%$.

Em 2002, ainda, o desempenho em leitura dos estudantes brasileiros foi de 403 pontos. Ou seja, aumentou-se o gasto por aluno desde então, mas o índice de desempenho variou pouco nessa área. Como mencionado, o Chile fez 459 pontos em leitura, mas - destaque-se - com o mesmo gasto por aluno que o Brasil, sem falar que países como Colômbia, México Uruguai obtiveram melhor pontuação, muito embora seu custo médio por aluno seja inferior ao do Brasil.

O Pisa ainda divulgou os sete níveis de proficiência (1b, 1a, 2, 3, 4, 5 e 6) em que se baseia para distribuir os resultados do desempenho dos estudantes em

\footnotetext{
${ }^{4}$ Meninos: 395 pontos. Meninas: 419 pontos.
} 
leitura.

Segundo a OCDE (2016 apud BRASIL..., 2016, p. 92), o letramento em leitura:

[...] refere-se a compreender, usar, refletir sobre e envolver-se com os textos escritos, a fim de alcançar um objetivo, desenvolver conhecimento e potencial e participar da sociedade.

Na escala das proficiências de leitura do Pisa - nível abaixo de 1B, 1B, 1A, 2, 3, 4, 5, 6, do menor para o maior -, $51 \%$ dos estudantes brasileiros não atingiram o nível 2. A OCDE estabelece o nível 2 como o patamar "necessário para que o estudante possa exercer plenamente sua cidadania." (INEP, 2016, p. 12).

Considerando esses dados, portanto, há que se refletir sobre o que nos coloca Macedo (2008 apud NOVAES, 2017) sobre a obrigatoriedade do ensino regular, ou seja, ainda que o estudo regular seja um direito e dever do Estado e da família, o que fazer se, na prática, a educação não acontece, não é efetiva ou se a escola não apresenta os recursos suficientes para que nela se aprenda?

Os resultados do Pisa, pode-se afirmar, vão de encontro ao plano ideal preconizado pela Base Nacional Comum Curricular (2018) para o componente Língua Portuguesa (Ensino Fundamental e Ensino Médio).

O modelo regular de ensino é resumido por Novaes (2017) como tendo: 1) sua estrutura dividida em educação infantil, educação fundamental (anos iniciais e anos finais) e ensino médio. E aqui nos interessam especialmente os anos finais em diante (faixa do Pisa). E 2) sua organização, tendo em vista o calendário escolar, da seguinte forma: ano letivo, promoção, série, ciclo, progressão continuada, reprovação e "aprovação automática". Todos os currículos devem ter base nacional comum e seguir, grosso modo, essa estrutura e organização.

Tendo em vista a avaliação do Pisa 2015 e a leitura agravante que se depreende do cenário retratado pelo programa, propomos aqui esclarecer o regime de homeschooling como possível alternativa ao modelo de formação da educação básica no Brasil. Conforme citado na "Introdução", o homeschooling é o regime de ensino dirigido a crianças e adolescentes e guiado pelos pais ou responsáveis, mas também, 
NOVAES, 2017, p. 36).

Como podemos inferir dos dados do Pisa - e, por que não, da realidade que nos cerca, haja vista os casos de bullying, violência, transgressão, uso de drogas, uso do espaço escolar para propaganda política, entre um sem número de casos veiculados na mídia todos os dias -, não é de se desprezar que a opção e o interesse pelo ensino domiciliar seja crescente. De 2011 a 2018, o número de famílias que optam pelo homeschooling cresceu $2.089 \%$, de 359 (observado) a mais de 7.500 (projetado) famílias, com estimativa de 17.214 famílias para 2020, conforme dados da Associação Nacional de Educação Domiciliar (ANED, [2019]).

O homeschooling difere, primeiramente, do ensino regular por apresentar diferentes formas de realização e prática:

[...] mediante um estudo estruturado (seguindo programas e cronogramas de atividades) ou um estudo livre baseado nos interesses das crianças; realizado dentro da casa ou em outros espaços livres e/ou locais públicos; com uso dos recursos educacionais locais ou não; ou mesmo de duas ou mais formas (BARBOSA, 2013, p. 17 apud NOVAES, 2017, p. 31-32).

Daí se depreendem alguns benefícios ou contribuições da educação domiciliar, segundo a Aned:

- Proporciona maior amadurecimento;

- Desenvolve a disciplina de estudo;

- Desenvolve o gosto pelo aprendizado;

- Desenvolve estratégias de aprendizado;

- Produz adultos seguros e com uma autoestima sólida;

- Favorece o empreendedorismo;

- Produz excelentes resultados acadêmicos (CONCEITO, 2019, não paginado).

Na pesquisa de Simone Novaes (2017) que abarcou estudo de caso com 12 brasileiros que experienciaram o homeschooling, 10 que vivem no Brasil e 2 que vivem nos Estados Unidos, a autora concluiu que os homeschoolers tornaram-se, principalmente, autodidatas. Novaes traz em sua reflexão a ideia de Ivan Illich, famoso pensador, "que se opôs à instituição escolar em sua teoria de desescolarização" porque a escola seria, para ele, um lugar de alienação, e não de formação. Na visão de alguns pais de homeschoolers, conforme traz Novaes, encontram-se justificativas como: a escola ser "altamente segregadora e definidora de classes, além de não propiciar um ambiente saudável para socialização, contrariando muitos que defendem ser este o seu papel." (NOVAES, 2017, p. 35) ou ainda a opção pelo homeschooling se justificava para que os filhos "se realizassem 
na área pessoal, profissional e se tornassem autodidatas" (NOVAES, 2017, p. 34). De fato, no caso da família Nunes, investigada por Novaes, os filhos homeschoolers ganharam prêmios em inovação de sistema de informação, eram empreendedores já na idade de 13-14 anos e criaram o primeiro site ainda adolescentes.

Já Fábio Schebella, em pesquisa apresentada ao Global Home Education Conference (Rio de Janeiro, 2016), atesta que os homeschoolers desenvolvem as mesmas habilidades e competências do estudante regular e vão além: "quando chegam ao mercado de trabalho se tornam eficientes e [...] são as pessoas mais desejadas nas Organizações" (NOVAES, 2017, p. 42).

Nas famílias optantes pelo homeschooling, não há exatamente um padrão na organização dos estudos, já que algumas buscam professores particulares ou atividades em clubes, escolas de idiomas, método kumon, museus, parques, feiras de ciências etc., outras seguem o programa do ensino regular ou ainda optam por deixar o ensino livre, para que o estudante possa escolher e "passear" pelos temas da forma como desejar. A rotina também pode variar, sendo mais flexível ou mais rígida. A internet também parece ser uma aliada da educação domiciliar, uma vez que os pais ou tutores podem buscar cursos on-line que não encontrariam na própria cidade. (NOVAES, 2017).

Em depoimento de uma mãe de homeschooler, esta relata que optou pela educação clássica, atenta à diretrizes do MEC, mas ampliando as disciplinas: os filhos estão aprendendo "lógica formal, línguas antigas, como o latim e o grego (em um curso online em que pagamos uma única matrícula), filosofia, teologia, entre outros assuntos." (SANTOS apud NOVAES, 2017, p. 43).

$\mathrm{RJ} 1^{5}, 32$ anos, praticou o homeschooling por quase toda a vida de estudante e conta que, para estudar as disciplinas de português e inglês, na etapa que

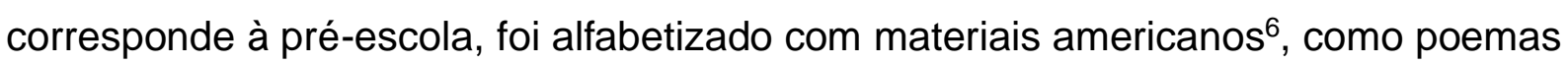
e vídeos. No ensino fundamental, usou cartilhas. Já o ensino médio foi realizado a distância, por meio do Telecurso 2000, Instituto Universal Brasileiro e videoaulas. Além das disciplinas comuns ao ensino regular, cursou desenho, música, dança,

\footnotetext{
${ }^{5}$ A autora Novaes (2017) optou por usar siglas para identificar os homeschoolers pesquisados e entrevistados. RJ1 é um homeschooler com 32 anos de idade, cursou apenas um ano (ensino médio) na escola regular, é especialista em idiomas e empresário (escola de idiomas).

${ }^{6}$ Americanos porque na época em que RJ1 estudava não havia muitos materiais direcionado ao homeschooling, plano de aulas, organização de aulas em casa em português, por isso a maior quantidade de materiais vinha dos Estados Unidos, país conhecido pelo número de optantes pelo homeschooling. Por isso também muitas crianças e adolescentes brasileiros acabam sendo alfabetizados nas duas línguas: português e inglês.
} 
artesanato, culinária, fotografia, webdesign, design gráfico, arte, teatro, entre outros. (NOVAES, 2017).

RJ2, 24, nunca frequentou a escola regular, mas conta que até a $4^{\mathrm{a}}$ série estudou com outras crianças da mesma idade, em turmas organizadas pelos pais/tutores, de segunda a sexta-feira, e durante a manhã. Como RJ1, também usava material americano para estudar. Depois passou também a estudar por meio de livros de diversas editoras brasileiras. Fora das aulas, ajudava a mãe em casa, fazia aulas de piano, flauta e balé. RJ3, 19 anos, adotou livros didáticos complementados, pelos pais, com passeios, filmes, projetos sociais, curso de inglês para homeschoolers etc. No geral, a pesquisa de Novaes mostrou que a maioria dos homeschoolers entrevistados praticava a leitura de livros nas mais diversas áreas e também literatura, poemas, músicas, e muitos não tinham "grades" rígidas, mas estudavam de acordo com o interesse e com os conhecimentos que já tinham.

Os entrevistados também apontaram alguns pontos positivos da opção pelo homeschooling, quais sejam: poder conviver com a família, acesso a outras culturas, possibilidade de desenvolver outras habilidades "naturais", flexibilidade de tempo e método, autonomia, qualidade do estudo (pode se "aprofundar" em estudos mais complexos), melhor concentração, leitura prazerosa e educativa, dinamismo, criar o hábito do estudo, expansão dos conhecimentos por meio de idas ao museu, ao cinema, a exposições etc., personalização da educação (sentiam que o método e a organização dos estudos era moldada para o ritmo deles), não rigidez nos estudos (podiam avançar nos estudos, estudar temas mais complexos em vez de aguardar entrar na série ideal, como na escola regular), e, por fim, autodidatismo, ou seja, aprender sem professor ou mediador (NOVAES, 2017). Além disso, os homeschoolers relatam, de forma geral, que conseguem aprender mais "rápido" por conta do dinamismo do estudo e da flexibilidade de tempo.

Novaes também avaliou a percepção dos homeschoolers em relação aos eixos propostos na BNCC e encontrou que a maioria dos entrevistados considera que foi "plenamente comtemplada" no eixo de formação "Expressar-se como sujeito criativo e sensível através de diferentes linguagens", "Envolvimento em diferentes práticas de letramento que permitem sua expressão e atuação no mundo" e "Participação no mundo letrado e capacidade de aprender ao longo da vida", respostas que vão de encontro aos resultados do Pisa 2015. Como mencionado, na escala das proficiências de leitura do Pisa - nível abaixo de 1B, 1B, 1A, 2, 3, 4, 5, 6, 
do menor para o maior -, 51 \% dos estudantes brasileiros não atingiram o nível 2. A OCDE estabelece o nível 2 como o patamar "necessário para que o estudante possa exercer plenamente sua cidadania." (INEP, 2016, p. 12). As respostas ainda contrastam como os resultados do Prova Brasil, onde se contatou que " $40 \%$ dos alunos concluem o ensino fundamental sem saber interpretar textos" (VEJA apud NOVAES, 2017, p. 87).

Em estudo recente, que investigou 13 famílias optantes pelo homeschooling em Aracaju, Pessoa (2019) encontrou que a educação dos homeschoolers normalmente consegue ultrapassar o roteiro da escola regular. Pessoa ainda se concentrou em descrever os métodos utilizados pelas famílias brasileiras nos estudos, quais sejam:

- Método eclético: nesse método o estudo é guiado por múltiplas metodologias, a depender do objetivo e do contexto.

- Método "estudo de unidade" ou "estudo por temas": uma determinada temática vai ser estudada com base em múltiplas disciplinas ou áreas do conhecimento, buscando atingir áreas de interesse da criança ou adolescente para que se equilibrem com áreas de menor interesse. Os pais também poder criar unidades de estudo com base no interesse da criança ou adolescente.

- Método "Montessouri": esse método permite à criança autoeducar-se e praticar a liberdade. Numa sala, por exemplo, são ordenados vários objetos, e a criança pode escolher com qual trabalhar; ao finalizar deve limpá-lo e guardá-lo para outra criança, e deve aguardar caso o objeto esteja sendo utilizado. Esse método busca fazer a criança exercitar a disciplina, a paciência e a eliminação da competição.

- Método "escola em casa": trata-se, grosso modo, da "transferência e adaptação dos métodos e materiais utilizados na escola para dentro de casa." (PESSOA, 2019, p. 59). Ou seja, adaptam-se currículos prontos, seguem-se roteiros e propostas, por exemplo, do MEC, as matérias são as mesmas da escola regular, há horários e dias determinados de estudo, aplicação de avaliações ou contratação de professores particulares, e assim por diante.

- Método "educação clássica": conhecido ainda como "método clássico medieval", consiste no estudo do trivium (gramática, lógica e retórica) e quadrivium (aritmética, geometria, música e astronomia), ou seja, das sete artes liberais, ainda com forte caráter metafísico, sendo um método mais complexo do que os demais. 
No trivium, por exemplo, o aluno deveria, primeiro, aprender a estrutura da língua; depois, a usar o idioma, refinando-se gradualmente em argumentação, deteç̧ão de falácias etc.; por último, ele aprendia a realmente se expressar na língua estudada. (GREGGERSEN, 2010 apud PESSOA, 2019, p. 67). Seguindo esses passos, o estudante, além de aprender a língua, aprenderia "a ensinar a si próprio" (BLUEDORN; BLUEDORN, 2016 apud PESSOA, 2019, p. 67).

- Método "educação desescolarizada" (unschooling): esse método é o oposto do método "escola em casa", pois "privilegia o interesse do aluno em oposição a um currículo, rotinas e calendários pré-fixados” (PESSOA, 2019, p. 63).

- Método "Charlotte Mason": nesse método o foco da Mason foi habilitar a criança à autoeducação. Há ênfase em livros, produção de cadernos sobre experiências como passeios (BLUEDORN; BLUEDORN, 2016 apud PESSOA, 2019), e a literatura é um diferencial em relação aos outros métodos. $\mathrm{Na}$ abordagem de Mason, as crianças não devem ser submetidas a literaturas infantis de baixa complexidade, "abobalhadas", como afirma Mason, mas sim a livros "vivos, ricos" (HASWELL, 2018, p. 7 apud PESSOA, 2019, p. 71). Aliás, vida é outro ponto diferente dessa abordagem, uma vez que Mason acredita que todo aprendizado deve ter relação com a realidade, ao estudante devem ser apresentados temas ligados à própria vida e aos próprios interesses.

Todos esses métodos, no entanto, podem mesclar-se, uma vez que a educação domiciliar os utiliza como guias, mas também a família ou o aluno pode fazer substituições, manter o ensino livre, em suma, pode-se personalizar o ensino para cada criança ou adolescente, fazer mudanças no planejamento visando ao melhor interesse da criança.

Os pais ou tutores podem ainda criar métodos próprios. Uma família entrevista por Pessoa (2019), por exemplo, retirou o filho da escola regular quando este tinha 13 anos. No primeiro ano de educação domiciliar, os pais optaram por organizar um programa de estudos voltado à leitura de livros, à escrita e à correção gramatical. O pai inicialmente indicava um livro (entre livros de ficção, biografias e outros), e o filho, ao ler o livro, registrava as palavras que desconhecia para ampliar seu léxico. Quando a leitura terminava, pai e filho discutiam sobre o tema do livro, e o homeschooler escrevia uma redação para que aprimorasse suas noções de gramática (coerência, coesão, ortografia etc.). Depois dessa fase inicial, em que o educando se dedicou principalmente à disciplina de português, ele foi introduzido a 
novas disciplinas, com objetivo de se qualificar no Exame Nacional do Ensino Médio (Enem). Para isso, o pai matriculou o filho em cursos pré-vestibular on-line, e o educando buscava ampliar os conhecimentos via internet, assistindo a vídeos pelo computador, tablet ou smartphone.

Nota-se que, para a educação domiciliar funcionar, no entanto, é preciso muita dedicação dos pais/tutores à educação dos filhos, e destes também, uma vez que a educação domiciliar busca aprimorar não só os conhecimentos, mas a autoeducação, o amor pelo estudo. Não obstante, as vantagens da educação domiciliar podem compensar esse esforço, uma vez que esta permite um estudo individualizado, mais troca de informações e convívio com os pais, com pessoas e colegas de idades diferentes, com interesses diferentes, com flexibilidade de dias e horários de estudo, de espaço de estudo (todo lugar pode funcionar como "sala de aula"), e principalmente o homeschooling trabalha o autodidatismo, que é uma habilidade que os aprendentes levarão para toda a vida. (PESSOA, 2019).

\section{CONSIDERAÇÕES FINAIS}

Tendo em vista trazer à luz uma alternativa à escola regular, principalmente na área de Língua Portuguesa, trouxemos neste breve trabalho alguns indicadores do Pisa 2015, indicadores que alertam para os baixos rendimentos dos nossos alunos em leituras mais avançadas.

De outro lado, as deficiências do ensino regular resultam na busca por novas formas de se educar, e uma modalidade que vem crescendo muito no Brasil e no mundo é o homeschooling, que pode criar um ambiente propício ao autodidatismo, ao ensino individualizado e ao ritmo de estudo do homeschooler.

Falamos também que os pais ou tutores que optam pela educação domiciliar podem escolher os métodos de ensino de acordo com os objetivos de estudo, inclusive o método conhecido como "escola em casa", onde se transportam o currículo, os horários, as disciplinas do ensino regular para serem aplicados em casa ou outros espaços fora da escola.

No entanto nossa proposta aqui também é mostrar que o caminho inverso é possível, ou seja, usar os métodos de homeschooling na educação regular, especialmente na disciplina de Língua Portuguesa (leitura), haja vista que 
[...] há obstáculos na aprendizagem de Língua Portuguesa no Brasil, uma realidade que interfere diretamente no desempenho escolar de uma elevada parte de educandos, que consideram deficitária a disciplina de LP, reduzida, em sua maior parte, à memorização de regras gramaticais (ANTUNES, 2003 apud CARDOSO, L. S.; BRITO, M. P. T. dos.; DERING, 2018, p. 97).

Um exemplo de sucesso desse caminho inverso é o da Escola da Ponte, em Portugal - país que vem subindo seus indicadores de educação -, cujo método é replicado por algumas escolas brasileiras, a exemplo da Emef Desembargador Amorim Lima, de São Paulo. No projeto da Escola da Ponte, a autonomia dos estudantes - uma das características do homeschooling - é o carro-chefe do ensinoaprendizagem. Essa escola pública estadual, localizada na cidade de São Tomé de Negrelos, ficou conhecida mundialmente por se afastar do ensino tradicional e pelas práticas educativas inovadoras. A escola não foca no sujeito professor, mas na liberdade de interesses do aluno; não usa o modelo o sistema de ciclos, de séries, como no Brasil. Lá, os próprios estudantes criam ruas regras e ritmos de estudo. O estudante escolhe o tema que gostaria de aprender ou pesquisar, convida outros alunos para sua "turma", independentemente da idade, para se juntar a ele, e todos podem solicitar a ajuda de um professor: por meio de uma solicitação formal, os alunos podem solicitar ajuda justificando seus objetivos e o que já aprenderam sobre o tema. Logo, alunos mais velhos estudam, ajudam e aprendem com alunos mais novos, e vice-versa, unidos por interesses comuns. Esse método também é usado no homeschooling, como mencionado: método "estudo de unidades" ou "estudo por temas".

No Projeto da Ponte, como mencionado, não há ciclos ou séries, mas núcleos: Iniciação, Consolidação e Aprofundamento, onde os alunos vão desenvolvendo as competências, mediados pelos Orientadores Educativos, que não são professores de disciplinas específicas, mas qualquer pessoa da comunidade escolar que o aluno escolher, incluindo os pais. O espaço central dessa escola é a biblioteca, onde os alunos e a comunidade se reúnem para discutir seus interesses educativos e também a organização da escola. Cada aluno tem um papel e responsabilidades para consigo mesmo, para com os colegas e para com a organização da Escola da Ponte.

Com esse exemplo, voltamos à nossa questão inicial para afirmar que o homeschooling pode trazer contribuições ao ensino regular que conhecemos hoje no Brasil. Os indicadores de educação no Brasil mostram que é preciso mudar, e muito, 
a maneira de entender a educação e os métodos de ensino a que estamos submetendo crianças e adolescentes; é preciso, portanto, desescolarizar um pouco nosso ensino para que possamos aprender a ser livres, e sendo livres podemos enxergar a educação como uma necessidade, e não como obrigação.

Tendo isso em vista, o "regime de ensino de crianças e de adolescentes [...] dirigido pelos pais ou por responsáveis." (BRASIL, 2019, p. 7), aliado ao ensino regular, pode trazer benefícios ao estudante de ensino regular no Brasil - tendo em vista os baixos rendimentos sinalizados pelo Pisa 2015.

\section{REFERÊNCIAS}

ANDRADE, Édison Padro de. A educação familiar desescolarizada como um direito da criança e do adolescente: relevância, limites e possibilidades na ampliação do direito à educação. 552 f. Tese (Doutorado em Educação) - Programa de PósGraduação em Educação, Faculdade de Educação, Universidade de São Paulo, 2014.

BARBOSA, Luciane Muniz Ribeiro. Ensino em casa no Brasil: um desafio à escola? 350 f. Tese (Doutorado em Educação) - Programa de Pós-Graduação em Educação, Faculdade de Educação, Universidade de São Paulo, São Paulo, 2013. Orientador: Romualdo Luiz Portela de Oliveira.

BASE NACIONAL COMUM CURRICULAR. 2019. Disponível em: http://basenacionalcomum.mec.gov.br. Acesso em: 13 jun. 2019.

BRASIL. Presidência da República. Lei no 9.394, de 20 de dezembro de 1996. Estabelece as diretrizes e bases da educação nacional. Disponível em: http://www.planalto.gov.br/ccivil_03/leis//9394.htm. Acesso em: 3 jun. 2019.

BRASIL. Ministério da Educação. Secretaria de Educação Fundamental. Parâmetros curriculares nacionais: terceiro e quarto ciclos do ensino fundamental: língua portuguesa. Brasília: SEF, 1998. 106 p. Disponível em: http://portal.mec.gov.br/seb/arquivos/pdf/portugues.pdf. Acesso em: 21 maio 2019.

BRASIL. Ministério da Educação/Instituto Nacional de Pesquisas Educacionais Anísio Teixeira. Resumo técnico - Resultados do índice de desenvolvimento da educação básica. Brasília: MEC/Inep, 2017.

BRASIL. Ministério da Educação. Base nacional comum curricular. Brasília: MEC, 14 dez. 2018.

BRASIL. Poder Executivo. Projeto de lei $n^{\circ}$ 2401/2019. Dispõe sobre o exercício do direito à educação domiciliar, altera a Lei no 8.069, de 13 de julho de 1990 - Estatuto da Criança e do Adolescente, e a Lei n 9.394, de 20 de dezembro de 1996, que 
estabelece as diretrizes e bases da educação nacional. Apresentação: 17 abr. 2019. Disponível https://www.camara.leg.br/proposicoesWeb/prop_mostrarintegra?codteor=1734553\& filename=PL+2401/2019. Acesso em: 20 abr. 2019.

BRASIL no Pisa 2015: análises e reflexões sobre o desempenho dos estudantes brasileiros. São Paulo: Fundação Santillana, 2016.

CARDOSO, L. S.; BRITO, M. P. T. dos.; DERING, R. DE O. A escola da ponte e o ensino de língua portuguesa: apontamentos e reflexões. Revista Falange Miúda (ReFaMi), Cuiabá, v. 3, n. 2, jul./dez. 2018.

CONCEITO. Associação Nacional de Educação Domiciliar (Aned), [2019]. Disponível em: https://aned.org.br/educacao-domiciliar/ed-sobre/ed-conceito. Acesso em: 22 abr. 2019.

GAITHER, Milton. Homeschooling in the United States: A review of select research topics. Pro-Posições, Campinas, v. 28, n. 2, maio/ago. 2017.

GERHARDT, Tatiana Engel; SILVEIRA, Denise Tolfo (org.). Métodos de pesquisa. Coord. Universidade Aberta do Brasil/UFRGS e curso de graduação tecnológica Planejamento e Gestão para o Desenvolvimento Rural da Sead/UFRGS. Porto Alegre: UFRGS, 2009.

HISTÓRICO. Associação Nacional de Educação Domiciliar (Aned), 2019. Disponível em: https://aned.org.br/educacao-domiciliar/ed-sobre/ed-historico. Acesso em: 22 abr. 2019.

IDEB. Instituto Nacional de Pesquisas Educacionais Anísio Teixeira (Inep/MEC), 20 out. 2015. Disponível em: http://portal.inep.gov.br/web/guest/ideb. Acesso em: 13 jun. 2019.

INSTITUTO NACIONAL DE PESQUISAS EDUCACIONAIS ANÍSIO TEIXEIRA (INEP). Pisa 2015: resultados da avaliação de leitura. Brasília: Inep; MEC, dez. 2016.

KLOH, Fabiana Ferreira Pimentel. Quando a escola não faz parte da biografia: depoimentos de vida em homeschooling. Revista Brasileira de Pesquisa (Auto) Biográfica (RBPAB), v. 1, n. 2, p. 343-355, maio/ago. 2016.

LEGAL status of homeschooling across the world. 24 jan. 2019. 1 mapa. Disponível em:

https://en.wikipedia.org/wiki/Homeschooling_international_status_and_statistics\#/me dia/File:Legality_of_Homeschooling_2019_Sept.svg. Acesso em: 17 ago. 2019.

NOVAES, Simone. Homeschooling no Brasil: um estudo sobre as contribuições do ensino domiciliar no desenvolvimento das competências individuais e na formação educacional. 116 f. 2017. Dissertação (Mestrado Profissional em Administração) Fundação Pedro Leopoldo, Pedro Leopoldo, 2017. 
PESSOA, Alexsandro Vieira. Práticas pedagógicas na educação domiciliar: um estudo de caso em Aracaju-SE. 123 f. 2019. Dissertação (Mestrado em Educação) Universidade Federal de Sergipe, São Cristóvão, 2019.

PROGRAMA Internacional de Avaliação de Estudantes (Pisa). Instituto Nacional de Pesquisas Educacionais Anísio Teixeira (Inep/MEC), 20 out. 2015. Disponível em: http://portal.inep.gov.br/pisa. Acesso em: 9 jun. 2019.

ORGANIZAÇÃO PARA A COOPERAÇÃO E DESENVOLVIMENTO ECONÓMICO (OECD). Programme for International Student Assessment (Pisa) - Results from Pisa 2015. [S. I.]: OECD, 2015.

ORGANIZAÇÃO PARA A COOPERAÇÃO E DESENVOLVIMENTO ECONÓMICO (OECD). Brasil no Pisa 2015: análises e reflexões sobre o desempenho dos estudantes brasileiros. São Paulo: Fundação Santillana, 2016.

OUTROS documentos. Instituto Nacional de Pesquisas Educacionais Anísio Teixeira (Inep/MEC), 21 fev. 2019. Disponível em: http://portal.inep.gov.br/web/guest/acoesinternacionais/pisa/outros-documentos. Acesso em: 9 jun. 2019.

RIBEIRO, Álvaro Manuel Chaves; PALHARES, José. O homeschooling e a crítica à escola: hibridismos e (des)continuidades educativas. Pro-Posições, v. 28, n. 2 (83), p. 57-84, maio/ago. 2017. 